\title{
COMPARAÇÃO DA VIABILIDADE DE SEMENTES DE Schizolobium parahyba (VELL.) BLAKE - LEGUMINOSAE CAESALPINIOIDEAE, PELOS TESTES DE GERMINAÇÃO E TETRAZÓLIO'
}

\author{
ROBÉRIO ANASTÁCIO FERREIRA',LUCIANA MAGDA DE OLIVEIRA², \\ OLÍVIA ALVINA OLIVEIRA TONETTI ${ }^{3}$, ANTONIOCLAUDIODAVIDE ${ }^{4}$
}

\begin{abstract}
RESUMO - Schizolobium parahyba (Vell.) Blake, conhecido como guapuruvu, pode ser utilizado na construção civil, na medicina popular e apresenta potencial para uso na recuperação de matas ciliares. Poucas informações são encontradas na literatura sobre avaliação da qualidade fisiológica de sementes dessa espécie, principalmente em relação a metodologias para realização dos testes de germinação e tetrazólio. Objetivou-se com este trabalho avaliar a influência da temperatura no teste de germinação e da concentração da solução no teste de tetrazólio para avaliação da viabilidade de sementes de $S$. parahyba. Sementes de dois lotes tiveram seus ápices cortados, as quais foram desinfestadas com hipoclorito de sódio e semeadas em bandejas de polietileno $(35 \times 20 \times 5 \mathrm{~cm})$, sobre areia peneirada, lavada e autoclavada $\left(120^{\circ} \mathrm{C}\right.$ por 20 minutos). As sementes foram submetidas à temperaturas constantes de $25^{\circ} \mathrm{C}, 30^{\circ} \mathrm{C}, 35^{\circ} \mathrm{C}$ sob luz contínua, e alternada de $20^{\circ}-30^{\circ} \mathrm{C}$ com 8 horas de luz na temperatura de $30^{\circ} \mathrm{C}$. As avaliações foram realizadas considerando-se a emergência de radícula, plântulas normais e índice de velocidade de germinação. Para o teste de tetrazólio, após a imersão das sementes em água por 48 horas, os tegumentos e o endosperma foram removidos e os embriões imersos nas soluções de tetrazólio a $0,05 \%$ e $0,1 \%$ e mantidos em câmara de germinação tipo BOD no escuro por cinco horas a $30^{\circ} \mathrm{C}$. Nos testes de germinação, as temperaturas de $25^{\circ} \mathrm{C}$ e $35^{\circ} \mathrm{C}$ proporcionam maior porcentagem e velocidade de germinação de sementes de S. parahyba e no teste de tetrazólio, a concentração $0,05 \%$ da solução permitie avaliar, com eficácia, a qualidade dos lotes de sementes desta espécie.
\end{abstract}

Termos para indexação: Teste de germinação, teste de tetrazólio, guapuruvu.

\section{VIABILITY COMPARISON OF Schizolobium parahyba (VELLL.) BLAKE SEEDS - LEGUMINOSAE CAESALPINIOIDEAE BY GERMINATION AND TETRAZOLIUM TEST}

\begin{abstract}
Schizolobium parahyba (Vell.) Blake, known guapuruvu can be used in building, popular medicine and to forest restoration in riparian areas. There are little informations about its seed quality evaluation. The objectives of this work were to evaluate the temperature influence on seed germination and to test the tetrazolium salt efficiency to determine seed viability. Two seed lots were harvested in Machado's region - MG. To accelerate the germination process seed dormancy was broken with a cut in apical part and the pathogens incidence reduction was done by washing in sodium hipoclorite (2\%). The seeds were sowed in poliethylen boxes $(35 \times 20 \times 5 \mathrm{~cm})$ with sand as washed and sterilized at $120^{\circ} \mathrm{C}$ by 20 minutes as substrate. Seeds were maintained at constant temperatures $25^{\circ} \mathrm{C}, 30^{\circ} \mathrm{C}$ and $35^{\circ} \mathrm{C}$ with continuous light and at alternate temperatures $20^{\circ}-30^{\circ} \mathrm{C}$, with 8 hours of light. The evaluations were realized considering root emergence, normal seedlings and speed germination index. For tetrazolium test, after immersion of seeds were immersed 48 hours and to seed coats removal the embryos were kept in tetrazolium salt at $0,05 \%$ and $0,1 \%$, at $30^{\circ} \mathrm{C}$ into a germination chamber (BOD) in dark by 5 hours. In the germination tests, the temperatures at $25^{\circ} \mathrm{C}$ and $35^{\circ} \mathrm{C}$ promoted higher germination percentage and speed germination index than the other temperatures. In the tetrazolium test the concentration $0,05 \%$ was better than $0,1 \%$ promoting a more efficient evaluation of seed viability of this species and all the classes obtained were efficient to evaluate the seed viability.
\end{abstract}

Index terms: germination test, tetrazolium test, guaригиvи.

${ }^{1}$ Submetido em 10/08/2006. Aceito para publicação em 14/05/2007;

1 Prof. Dr. Universidade Federal de Sergipe/Departamento de Engenharia Agronômica, Av. Marechal Rondon, S/N - Jardim Rosa Elze, CEP 49100-000, São Cristóvão, SE. e-mail: raf@ufs.br

2 Dra. Universidade Federal de Lavras/Departamento de Agricultura, CP 3037, CEP 37200-000, Lavras, MG. e-mail: lumagda@ufla.br

${ }^{3}$ Eng. Florestal, M.Sc. Universidade Federal de Lavras/Departamento de Ciências Florestais. e-mail: oaotonetti@ yahoo.com.br

${ }^{4}$ Prof. Dr. Universidade Federal de Lavras/Departamento de Ciências Florestais, e-mail: acdavide@ufla.br 


\section{INTRODUÇÃO}

Schizolobium parahyba (Vellozo) Blake - Fabaceae Caesalpinioideae, conhecida como guapuruvu ou umbela, é uma espécie heliófila, pioneira, que ocorre naturalmente desde a Bahia até o Rio Grande do Sul, comum em vegetação secundária e com bom potencial para uso na recuperação de matas ciliares, em locais não sujeitos à inundação. A sua madeira pode ser empregada na construção civil e para caixotaria em geral e a casca na medicina popular por possuir propriedades terapêuticas adstringentes (Carvalho, 2003). A espécie é vista, também, como fonte promissora de pasta para celulose, despertando interesse a seu respeito (Lorenzi, 1992).

A propagação do $S$. parahyba é realizada, principalmente, via sexuada, o que torna fundamental a avaliação da qualidade de suas sementes de maneira rápida e eficiente. $\mathrm{O}$ teste de germinação, método mais tradicionalmente utilizado para a análise da qualidade de sementes, determina a proporção de sementes capazes de produzir plântulas normais sob condições favoráveis de temperatura, luz, umidade, aeração e substrato (Bewley e Black, 1994).

Em relação à temperatura, a germinação só ocorrerá dentro de certos limites, acima ou abaixo dos limites superior e inferior, respectivamente, a germinação não ocorrerá. Dentro destes limites, existe uma faixa ótima de temperatura, na qual o processo ocorre com a máxima eficiência, obtendo-se o máximo de germinação no menor período de tempo. Um grande número de espécies florestais apresenta uma reação germinativa favorável a uma alternância de temperatura, à semelhança do que acontece em condições naturais, em que as temperaturas diurnas são mais altas que as noturnas (Medeiros, 2001). Essa necessidade pode estar associada à dormência das sementes, embora a alternância de temperatura possa acelerar a germinação de sementes não dormentes (Copeland e McDonald, 1995). Por outro lado, há espécies que respondem melhor quanto à viabilidade em laboratório, quando colocadas em temperaturas constantes.

As exigências quanto às condições citadas variam de acordo com a espécie e, geralmente, estão ligadas à adaptação da espécie no ambiente de origem; desta forma, há necessidade de serem determinadas temperaturas em que a eficiência do processo seja total. Em estudos realizados em sementes de sabiá (Mimosa caesalpiniaefolia), por exemplo, foi observado que a temperatura de $25^{\circ} \mathrm{C}$ proporcionou maior porcentagem de germinação e vigor em comparação a $20^{\circ} \mathrm{C}, 30^{\circ} \mathrm{C}$ e alternância de $20^{\circ}-30^{\circ} \mathrm{C}$ (Alves et al., 2002). Enquanto que, Varela et al. (2005) ao estudarem o efeito das temperaturas de 25,30 e $35^{\circ} \mathrm{C}$ na germinação de sementes de angelim-pedra (Dinizia excelsa), verificaram que esta não foi influenciada pela temperatura, mas que a 30 e $35^{\circ} \mathrm{C}$ houve maior desenvolvimento do hipocótilo e da raiz primária.

Outro método que vem sendo utilizado com êxito para avaliar a qualidade de sementes de espécies florestais é o teste de tetrazólio (Oliveira et al., 2005a; Oliveira et al., 2005b; Ferreira et al., 2004; Ferreira et al., 2001; Mendonça et al., 2001; Nascimento e Carvalho, 1998; Rodrigues e Santos, 1988). Neste teste, as sementes ficam em contato com uma solução incolor de cloreto de tetrazólio (2,3,5 cloreto trifenil de tetrazólio) que é absorvida pelos tecidos. Por meio de enzimas do grupo das desidrogenases, presentes nos tecidos vivos, o sal reage e gera um composto de coloração vermelha estável e não solúvel chamado formazan. Tecidos mortos, nos quais não há atividade dessas enzimas, permanecem descoloridos (Seidler, 1991). Deve-se considerar que, por apresentar resultados mais rápidos do que os testes de germinação, o teste de tetrazólio constitui-se uma alternativa viável para análise da qualidade de semente (França Neto, 1999), principalmente para as espécies florestais que apresentam dormência de sementes, como o $S$. parahyba. O teste de tetrazólio requer o conhecimento das estruturas das sementes a serem analisadas e a utilização de metodologia adequada para cada espécie (Vieira e Carvalho, 1994). A concentração de 0,075\% da solução de tetrazólio foi eficiente para avaliar a viabilidade de sementes de Pterodon pubescens (Ferreira et al., 2001), Senna multijuga e Senna macranthera (Ferreira et al., 2004). Para Peltophorum dubium, o uso da concentração de $0,1 \%$ permitiu determinar a qualidade de lotes de sementes dessa espécie (Oliveira et al., 2005a).

Há poucos relatos na literatura a respeito de pesquisas com o intuito de definir a melhor metodologia para a realização dos testes de germinação e tetrazólio em sementes de $S$. parahyba. Objetivou-se com este trabalho avaliar a influência da temperatura no teste de germinação e da concentração da solução no teste de tetrazólio para a avaliação da viabilidade de sementes de $S$. parahyba. 


\section{MATERIAL E MÉTODOS}

O trabalho foi realizado no Laboratório de Sementes Florestais do Departamento de Engenharia Florestal, da Universidade Federal de Lavras, MG. As sementes foram coletadas no chão após a dispersão, de quatro matrizes distantes no mínimo 50m entre si, situadas no município de MachadoMG, localizado a $21^{\circ} 40^{\prime} 28^{\prime \prime} \mathrm{Se}$ e $5^{\circ} 55^{\prime} 10^{\prime \prime} \mathrm{W}$, a $820 \mathrm{~m}$ de altitude (Brasil, 1992a), nos meses de janeiro (lote 1) e julho (lote 2). Após a coleta, as sementes foram acondicionadas em sacos de polietileno impermeáveis e armazenadas em câmara com controle de temperatura e umidade $\left(9^{\circ} \mathrm{C}\right.$ e $65 \%$ de umidade relativa) até a instalação dos experimentos.

O grau de umidade das sementes foi determinado segundo Brasil (1992b), pelo método de estufa a $103^{\circ} \pm$ $2^{\circ} \mathrm{C}$ por 17 horas, utilizando-se quatro repetições de $\pm 1 \mathrm{~g}$ de sementes e os resultados foram calculados com base no peso das sementes úmidas.

Para acelerar o processo germinativo, os ápices (região oposta à micrópila) das sementes foram cortados com tesoura de poda e, em seguida, fez-se a desinfestação com hipoclorito de sódio a $2 \%$ por dois minutos. As sementes foram enxaguadas em água destilada e semeadas em bandejas de polietileno $(35 \times 20 \times 5 \mathrm{~cm})$ sobre areia peneirada (com mesh de 0,05 a $0,8 \mathrm{~mm}$ ), lavada e autoclavada a $120^{\circ} \mathrm{C}$ por 20 minutos. Em cada bandeja foram colocados $1000 \mathrm{~mL}$ de areia. Para a avaliação da germinação, as bandejas foram mantidas em câmara de germinação BOD em temperaturas constantes de $25^{\circ} \mathrm{C}, 30^{\circ} \mathrm{C}$ e $35^{\circ} \mathrm{C}$ sob luz contínua, e alternada de $20-30^{\circ} \mathrm{C}$ com 8 horas de luz na temperatura de $30^{\circ} \mathrm{C}$. O substrato foi umedecido sempre que necessário, quando evidenciado o ressecamento na superfície. As avaliações foram realizadas a cada dois dias até o $30^{\circ}$ dia após a montagem do teste, considerando-se a protrusão de raiz primária e emergência de plântulas normais (Brasil, 1992b). Foi avaliado, ainda, o índice de velocidade de germinação (IVG) das sementes, segundo Maguire (1962).

Para a realização do teste de tetrazólio, as sementes de S. parahyba foram submersas em água destilada por 48 horas (a partir de pré-ensaio com tempo variando de 14 a 48 horas), os tegumentos e o endosperma foram removidos e os embriões foram imersos nas soluções de tetrazólio a $0,05 \%$ e $0,1 \%$, e mantidos em câmara de germinação BOD, no escuro, por 5 horas a $30^{\circ} \mathrm{C}$. Após este período, foram lavados em água destilada e cortados longitudinalmente na linha de sutura dos cotilédones para avaliação do eixoembrionário e cotilédones (Figura 1). As avaliações foram realizadas com auxílio de lupa estereoscópica Zeiss (4x) para a determinação da viabilidade, de acordo com as categorias estabelecidas e descritas abaixo:

Categoria 1 - (semente viável): embrião com coloração rosa, tecidos com aspecto normal e firme, e interior dos cotilédones com coloração mais clara;

Categoria 2 - (semente viável): menos de $50 \%$ dos cotilédones descoloridos ou danificados não afetando a região de ligação com o eixo-embrionário, demais regiões com coloração rosa e tecidos firmes;

Categoria 2A: cotilédones com descoloração no ápice, na parte interna e externa;

Categoria 2B: cotilédones com descoloração no centro interno e na parte externa;

Categoria 2C: pequenas manchas no ápice e lateral dos cotilédones;

Categoria 3 - (semente inviável): cotilédones com mais de $50 \%$ da sua área manchada;

Categoria 3A: eixo-embrionário com coloração normal;

Categoria 3B: eixo-embrionário descolorido;

Categoria 4 - (semente inviável): embrião com deformações físicas (má-formação) e tecidos flácidos;

Categoria 5 - (semente inviável): cilindro central do eixoembrionário com coloração vermelho-intensa;

Categoria 6 - (semente inviável): embrião com dano na região da plúmula e mais de $50 \%$ da região dos cotilédones com manchas vermelho-intensas.

Os experimentos foram realizados em delineamento inteiramente casualizado, em esquema fatorial $2 \times 4$ (dois lotes e quatro temperaturas), com quatro repetições de 25 sementes para avaliação da germinação e vigor e, $2 \times 2$ (duas temperaturas e duas concentrações) para comparação da eficiência do tetrazólio. Para as análises estatísticas foi empregado o programa SANEST, e as médias dos tratamentos de viabilidade (germinação e tetrazólio) foram comparadas pelo teste de Tukey a 5\% (Zonta e Machado, 1986). 


\section{RESULTADOS E DISCUSSÃO}

No estudo do efeito da temperatura na germinação de sementes de $S$. parahyba foi observado para o lote 1 (grau de umidade $=7,8 \%$ ), resultados superiores de emergência radicular nas temperaturas constantes, não havendo diferença estatística entre elas e entre a temperatura constante de $30^{\circ} \mathrm{C}$ e alternada de $20^{\circ}-30^{\circ} \mathrm{C}$. Para o lote 2 ( grau de umidade $=8,2 \%$ ) não foram observadas diferenças significativas entre as temperaturas constantes e alternada. O mesmo comportamento, para ambos os lotes, foi observado nos valores de IVG, em relação à protrusão radicular. Na comparação entre os dois lotes, foi observada diferença significativa apenas na temperatura alternada, quando o lote 2 foi superior ao lote 1 (Tabela 1 ).

As temperaturas de $25^{\circ} \mathrm{C}$ e $35^{\circ} \mathrm{C}$ proporcionaram maior porcentagem e velocidade de germinação, na avaliação de plântulas normais, quando comparadas às temperaturas de $30^{\circ} \mathrm{C} \mathrm{e} 20^{\circ}-30^{\circ} \mathrm{C}$, para ambos os lotes (Tabela 1 ). A obtenção de menores valores de germinação na temperatura alternada pode ser devido ao fotoperíodo utilizado, visto que, de acordo com Bianchetti e Ramos (1981), a espécie apresenta muita exigência quanto à luz.

Além da luz, outros fatores influenciam a resposta das sementes à temperatura de germinação, como substrato e umidade. Em trabalho realizado por Ramos et al. (2006) foi observado que o melhor desempenho germinativo de sementes de $S$. amazonicum foi alcançado nas temperaturas de $25^{\circ} \mathrm{C}, 30^{\circ} \mathrm{C}$ e $35^{\circ} \mathrm{C}$, com as quantidades de água de 2,5 e 3,0 vezes o peso do papel de germinação, e a velocidade do processo foi favorecida pelas temperaturas de $30^{\circ} \mathrm{C}$ e $35^{\circ} \mathrm{C}$ e pela quantidade de água equivalente a 3,0 vezes o peso do papel. Já Ramos et al. (1995) recomendaram a utilização das temperaturas de $25^{\circ} \mathrm{C}$ e $30^{\circ} \mathrm{C}$, em substrato areia, para a realização do teste de germinação em sementes de S. parahyba.

A escolha do recipiente também pode influenciar o resultado final do teste, como foi verificado nesse experimento. Apesar de serem observadas, na temperatura de $25^{\circ} \mathrm{C}, 95 \%$ e $89 \%$ de emergência radicular para os lotes 1 e 2 , respectivamente, o somatório do valor percentual de plântulas normais e anormais foram de $56 \%$ para o lote 1 e $61 \%$ para o lote 2 (Tabelas 1 e 2). Essas diferenças podem ter sido decorrentes da quantidade de substrato utilizada nas bandejas, que pelo rápido crescimento radicular, não foi suficiente para promover o estabelecimento das plântulas até a obtenção das demais estruturas essenciais para avaliação do teste. Os diferentes substratos comumente recomendados variam entre si em sua composição, toxidade às sementes, associação com patógenos, aeração e capacidade de retenção de umidade (Scalon et al., 1993), e para sua escolha deve-se levar em consideração a facilidade que o mesmo oferece para o perfeito desenvolvimento das plântulas, realização das contagens e avaliações. Desta forma, sugere-se a utilização de outro tipo de substrato ou uma maior quantidade nas bandejas, superior aos $1000 \mathrm{~mL}$ utilizados.

Em relação ao teste de tetrazólio, observou-se que, para o lote 1 , os resultados obtidos na concentração de $0,05 \%$ não diferiram dos percentuais alcançados no teste de germinação a $35^{\circ} \mathrm{C}$; enquanto que, a concentração de $0,1 \%$ subestimou a viabilidade do lote. Já para o lote 2, não foram observadas diferenças significativas entre os testes de tetrazólio e germinação (Tabela 3). A concentração de $0,05 \%$ da solução de tetrazólio permitiu, ainda, uma coloração mais nítida dos embriões quando comparada à concentração de $0,1 \%$, o que facilitou a análise visual da viabilidade.

Pesquisas com sementes de Fabaceae indicam que em concentrações mais baixas os resultados de viabilidade parecem apresentar uma maior correspondência com os testes de germinação do que em concentrações mais elevadas do sal de tetrazólio, como observado para sementes de Pterodon pubescens (Ferreira et al., 2001), Senna multijuga e Senna macranthera (Ferreira et al., 2004).

Deve-se considerar que as classes de viabilidade obtidas para o teste de tetrazólio, com base nos resultados para as sementes de Schizolobium parahyba, foram eficientes para a determinação da viabilidade desta espécie. Portanto, em caso de necessidade para se determinar mais rapidamente a viabilidade de sementes em análises laboratoriais sugere-se o seu uso, uma vez que pode-se obter resultados mais rápidos em relação aos testes de germinação. De modo, semelhante a Schizolobium parahyba, Ferreira et al. (2001) e Ferreira et al. (2004), também recomendam o uso do teste de tetrazólio para avaliação mais rápida da viabilidade de sementes de Pterodon pubescens e Senna multijuga e Senna macranthera, respectivamente. 

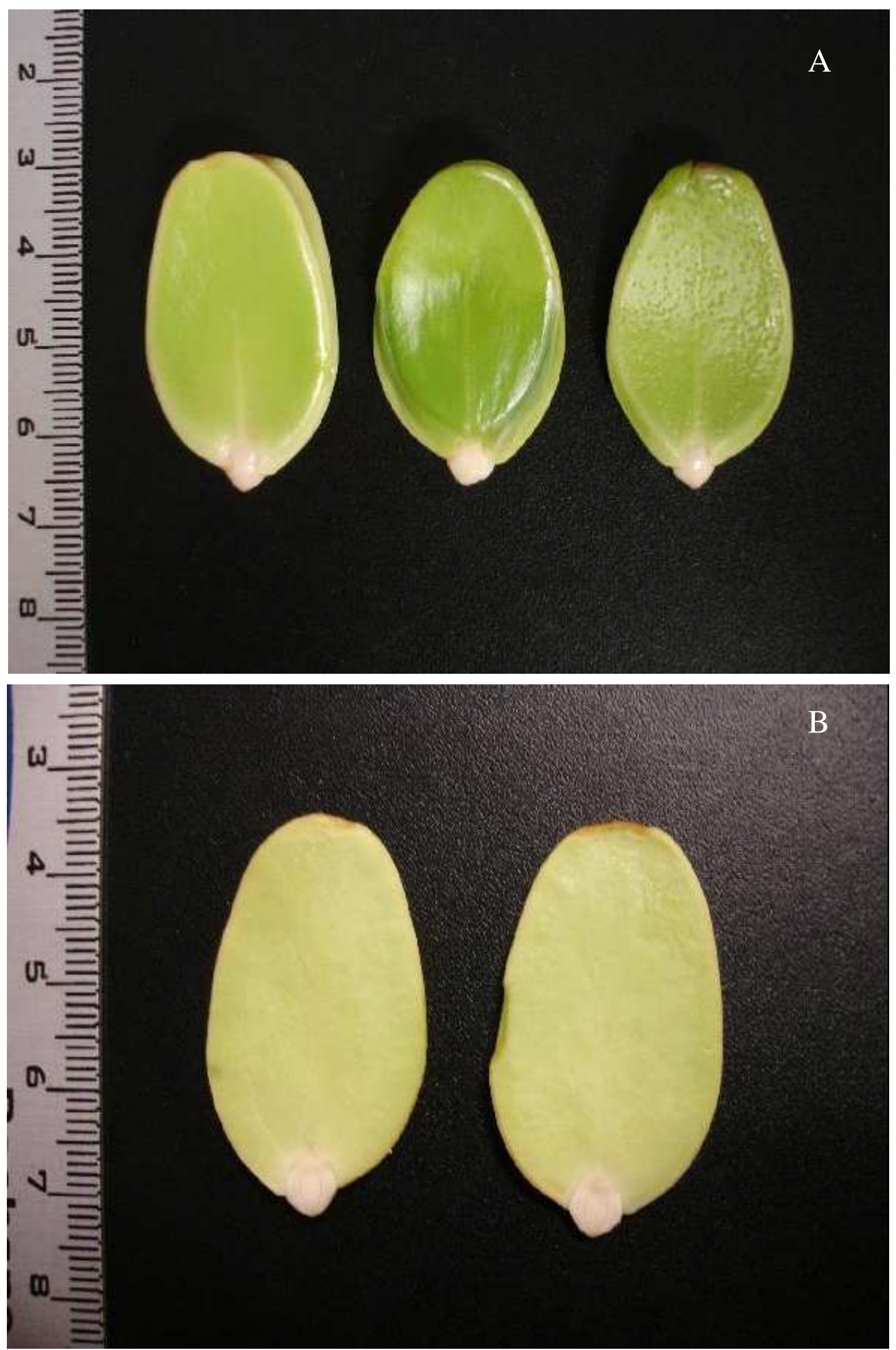

FIGURA 1. A- Embriões fechados de Schizolobium parahyba. B - embrião após corte longitudinal, com detalhe do eixo-embrionário e cotilédones para avaliação dos tecidos. 
TABELA 1. Resultados de emergência de raiz primária (ER), plântulas normais (PN) e índice de velocidade de germinação (IVG), em dois lotes sementes de Schizolobium parahyba, obtidos por meio do teste de germinação, em diferentes temperaturas.

\begin{tabular}{|c|c|c|c|c|c|c|c|c|}
\hline & \multicolumn{2}{|c|}{$\operatorname{ER}(\%)$} & \multicolumn{2}{|c|}{ IVG (ER) } & \multicolumn{2}{|c|}{$\mathbf{P N}$} & \multicolumn{2}{|c|}{ IVG (PN) } \\
\hline & \multicolumn{2}{|c|}{ Lote } & \multicolumn{2}{|c|}{ Lote } & \multicolumn{2}{|c|}{ Lote } & \multicolumn{2}{|c|}{ Lote } \\
\hline $\mathbf{T}^{\mathbf{0}} \mathrm{C}$ & 1 & 2 & 1 & 2 & 1 & 2 & 1 & 2 \\
\hline 25 & 95 a $\mathrm{A}$ & 89 a A & 3,36 a $A$ & 3,49 a $A$ & 38 a $A$ & 43 a A & 0,68 a B & 0,79 a $A$ \\
\hline 30 & $82 \mathrm{ab} A$ & 74 a A & 3,55 a $A$ & 2,74 a $A$ & $18 \mathrm{bc} \mathrm{A}$ & $24 \mathrm{~b} \mathrm{~A}$ & $0,28 \mathrm{~b} \mathrm{~B}$ & $0,58 \mathrm{~b} \mathrm{~A}$ \\
\hline 35 & 84 a A & 82 a $A$ & 2,94 a A & 2,90 a $\mathrm{A}$ & $23 \mathrm{ab} B$ & 45 a A & $0,41 \mathrm{ab} B$ & 0,82 a $A$ \\
\hline $20-30$ & $68 \mathrm{~b} \mathrm{~B}$ & 80 a A & 1,83 b B & 2,35 a A & $1 \mathrm{c} \mathrm{B}$ & $14 \mathrm{~b} \mathrm{~A}$ & $0,01 \mathrm{c} \mathrm{B}$ & 0,15 c A \\
\hline
\end{tabular}

Médias seguidas de mesma letra minúscula nas colunas e maiúscula nas linhas não diferem entre si pelo teste de Tukey a 5\%.

TABELA 2. Porcentagens de plântulas anormais (PA), sementes mortas (SM), sementes duras (SDuras) e emergência de radícula (ER)obtidas no final do teste de germinação em dois lotes de sementes de Schizolobium parahyba, submetidos a diferentes temperaturas.

\begin{tabular}{cccccc}
\hline Lotes & T $\left({ }^{\mathbf{0}} \mathbf{C}\right)$ & PA & SM & SDuras & ER \\
\hline $\mathbf{1}$ & 25 & 18 & 5 & 0 & 39 \\
& 30 & 19 & 8 & 10 & 45 \\
& 35 & 17 & 16 & 0 & 44 \\
& $20-30$ & 38 & 32 & 0 & 29 \\
\hline $\mathbf{2}$ & 25 & 18 & 11 & 0 & 28 \\
& 30 & 32 & 26 & 0 & 18 \\
& 35 & 20 & 18 & 0 & 17 \\
& $20-30$ & 40 & 20 & 0 & 26 \\
\hline
\end{tabular}

TABELA 3. Viabilidade de sementes de Schizolobium parahyba obtida pelos testes de germinação (TG) (emergência de radícula) e tetrazólio (TZ).

\begin{tabular}{ccc}
\hline & \multicolumn{3}{c}{ Lotes } \\
\hline & \multicolumn{1}{c}{ Viabilidade (\%) } \\
Tratamentos & $95,0 \mathrm{a}$ & $\mathbf{2}$ \\
\hline $\mathrm{TG}-25^{\circ} \mathrm{C}$ & $84,0 \mathrm{ab}$ & $89,0 \mathrm{a}$ \\
$\mathrm{TG}-35^{\circ} \mathrm{C}$ & $75,0 \mathrm{bc}$ & $82,0 \mathrm{a}$ \\
$\mathrm{TZ}-0,05 \%$ & $67,0 \mathrm{c}$ & $88,0 \mathrm{a}$ \\
$\mathrm{TZ}-0,1 \%$ & $73,0 \mathrm{a}$ \\
\hline
\end{tabular}

Médias seguidas de mesma letra minúscula nas colunas não diferem entre si pelo teste de Tukey a $5 \%$. 


\section{CONCLUSÕES}

As temperaturas de $25^{\circ} \mathrm{C}$ e $35^{\circ} \mathrm{C}$ proporcionam maiores porcentagem e velocidade de germinação de sementes de guapuruvu (Schizolobium parahyba);

A concentração 0,05\% da solução de tetrazólio permite avaliar, com eficácia, a qualidade dos lotes de sementes desta espécie.

As classes de viabilidade obtidas para avaliação do teste de tetrazólio podem ser empregadas para determinar mais rapidamente a viabilidade de sementes de Schizolobium parahyba, quando comparado ao teste de germinação.

\section{REFERÊNCIAS}

ALVES,E.U.;PAULA, R.C.;OLIVEIRA, A.P.;BRUNO,R.L.A.;DINIZ, A.A. Germinação de sementes de Mimosa caesalpiniaefolia Benth. em diferentes substratos e temperaturas. Revista Brasileira de Sementes, Brasília, v.24, n.1, p.169-178, 2002.

BEWLEY, J.D.; BLACK, M. Seeds: physiology of development and germination, 2 ed. Plenum Press: New York, 1994. 455p.

BIANCHETTI, A.; RAMOS, R. Quebra de dormência de sementes de guapuruvu (Schizolobium parahyba (Vellozo) Blake). Boletim de Pesquisa Florestal, Colombo, n.3, p.69-76, dez.1981.

BRASIL. Ministério da Agricultura e Reforma Agrária. Normais Climatológicas de 1961-1990. Brasília: Secretaria Nacional de Irrigação/Departamento Nacional de Meteorologia, 1992a. 84p.

BRASIL. Ministério da Agricultura e Reforma Agrária - MARA. Regras para análise de sementes. Brasília: SNDA/DNDV/CLAV, 1992b. 362p.

CARVALHO, P.E.R. Espécies arbóreas brasileiras: recomendações silviculturais de espécies florestais. Brasília: EMBRAPA Informação Tecnológica; Colombo: EMBRAPA/ CNPF, 2003. v.1, 1039p.

COPELAND, L.O.; MCDONALD, M.B. Principles of Seed Science and Technology. New York: Chapman \& Hall, 1995. 409p.

FERREIRA, R.A.; DAVIDE, A.C.; MOTTA, M.S. Vigor e viabilidade de sementes de Senna multijuga (Rich.) Irwin et Barn. e Senna macranthera (Collad.) Irwin et Barn., num banco de sementes em solo de viveiro. Revista Brasileira de Sementes, Brasília, v.26, n.1, p.24-31, 2004.

FERREIRA, R.A.; VIEIRA,M.G.G.C.; VONPINHO,E.V.R.; TONETTI, O.A.O. Morfologia da semente e de plântulas e avaliação da viabilidade da semente de sucupira-branca (Pterodon pubescens Benth. - Fabaceae) pelo teste de tetrazólio. Revista Brasileira de Sementes, Brasília, v.23, n.1, p.108-115, 2001.

FRANÇA NETO, J.B. Teste de tetrazólio para determinação do vigor de sementes. In: KRYZANOWSKI, F.C.; VIEIRA, R.D.; FRANÇA NETO, J.B. (Ed.). Vigor de sementes: conceitos e testes. Londrina: ABRATES, 1999. p.8.1-8.28.
LORENZI, H. Árvores Brasileiras: manual de identificação e cultivo de plantas arbóreas nativas do Brasil. Nova Odessa: Editora Plantarum, 1992.368p.

MAGUIRE, J.D. Speed of germination-aid in selection and evaluation for seedling emergence and vigor. Crop Science, Madison, v.1, n.1, p.176-177, 1962.

MEDEIROS, A.C.S. Aspectos de dormência em sementes de espécies arbóreas. EMBRAPA, 2001. 12p. (Circular Técnica).

MENDONÇA, E.A.F.; RAMOS, N.P.; PAULA, R.C. Viabilidade de sementes de Cordia trichotoma (Vellozo) Arrabida ex Steudel (louro-pardo) pelo teste de tetrazólio. Revista Brasileira de Sementes, Brasília, v.23, n.2, p.64-71, 2001.

NASCIMENTO, W.M.O.; CARVALHO, N.M. Determinação da viabilidade de sementes de jenipapo (Genipa americana L.) através do teste de tetrazólio. Revista Brasileira de Sementes, Brasília, v. 20, n. 2, p. 470-474, 1998.

OLIVEIRA, L.M.; CARVALHO, M.L.M.; DAVIDE, A.C. Teste de tetrazólio para avaliação da qualidade de sementes de Peltophorum dubium (Sprengel) Taubert - Leguminosae Caesalpinioideae. Revista Cerne, Lavras, v.11, n.2., p.159-166. 2005a.

OLIVEIRA, L.M.; CARVALHO, M.L.M.; NERY, M.C. Teste de tetrazólio em sementes de Tabebuia serratifolia Vahl Nich. e $T$. impetiginosa (Martius ex A. P. de Candolle) Standley - Bignoniaceae. Revista Ciência Agronômica, Fortaleza, v.36, n.2, 2005b.

RAMOS, A.; BIANCHETTI, A.; MARTINS, E.G.; FOWLER, J.A.P.; ALVES, V.F. Substratos e temperaturas para a germinação de sementes de guapuruvu (Schizolobium parahyba). EMBRAPA, Comunicado técnico, n.7, p.1. 1995.

RAMOS, M.B.P.; VARELA, V.P.; MELO, M.F.F. Influência da temperatura e da água sobre a germinação de sementes de paricá (Schizolobium amazonicum Huber ex Ducke - LeguminosaeCaesalpinioideae). Revista Brasileira de Sementes, Brasília, v.28, n.1,p.163-168, 2006.

RODRIGUES, F.C.M.P.; SANTOS, N.R.F. Teste de tetrazólio. In: RODRIGUES, F.C.M.P. Manual de análise de sementes florestais. Campinas: Fundação Cargill, 1988. 100 p.

SCALON, S.P.Q.; ALVARENGA, A.A.; DAVIDE, A.C.. Influência do substrato, temperatura, umidade e armazenamento sobre a germinação de sementes de pau-terra (Platycyamus regnelli, Benth.). Revista Brasileira de Sementes, Brasília, v.15, n.1, p.143-146, 1993.

SEIDLER, E. The tetrazolium-formazan system: Design and histochemistry. Progress in Histochemistry and Cytochemistry, Stuttgart, v.24, n.1, p.1-86, 1991.

VARELA, V.P.; RAMOS, M.B.; MELO, M.F.F. Umedecimento do substrato e temperatura na germinação de sementes de Angelimpedra (Dinizia excelsa Ducke). Revista Brasileira de Sementes, Brasília, v.27, n.2, p.130-135, 2005.

VIEIRA, R.D.; CARVALHO, N.M. Testes de vigor em sementes. Jaboticabal: FUNEP/UNESP, 1994. 164p.

ZONTA, E.P.; MACHADO, A.A. Sistema de análise estatística para microcomputadores - SANEST. Pelotas: UFPel, Instituto de Física e Matemática, 1986. 150p. 